\title{
Significant Need for a French Network of Expert Centers Enabling a Better Characterization and Management of Treatment-Resistant Depression (Fondation FondaMental)
}

OPEN ACCESS

Edited by:

Gianluca Serafini,

University of Genoa, Italy

Reviewed by:

Mirko Manchia,

Dalhousie University, Canada

Serafim Carvalho,

Hospital de Magalhães Lemos,

Portugal

${ }^{*}$ Correspondence:

Antoine Yrond

antoineyrondi@gmail.com

Specialty section: This article was submitted to Mood and Anxiety Disorders,

a section of the journal

Frontiers in Psychiatry

Received: 29 August 2017 Accepted: 06 November 2017 Published: 24 November 2017

Citation:

Yrondi A, Bennabi D, Haffen E, Garnier M, Bellivier F, Bourgerol T, Camus V, D'Amato T, Doumy O,

Haesebaert $F$, Holtzmann J,

Lançon C, Vignaud P, Moliere F, Nieto I, Richieri RM, Domenech P,

Rabu C, Mallet L, Yon L, Schmitt L,

Stephan F, Vaiva G, Walter $M$,

Llorca PM, Courtet P, Leboyer M

El-Hage W and Aouizerate B (2017)

Significant Need for a French Network of Expert Centers Enabling a

Better Characterization and Management of Treatment-Resistant Depression (Fondation FondaMental).

Front. Psychiatry 8:244.

doi: 10.3389/fpsyt.2017.00244
Antoine Yrondi ${ }^{*}$, Djamila Bennabi ${ }^{2}$, Emmanuel Haffen ${ }^{3}$, Marion Garnier $^{4}$, Frank Bellivier ${ }^{5}$, Thierry Bourgerol ${ }^{6}$, Vincent Camus ${ }^{7}$, Thierry D'Amato ${ }^{8}$, Olivier Doumy ${ }^{9}$, Frédéric Haesebaert ${ }^{8}$, Jérôme Holtzmann ${ }^{6}$, Christophe Lançon ${ }^{10}$, Philippe Vignaud ${ }^{8}$, Fanny Moliere ${ }^{11}$, Isabel Nieto ${ }^{5}$, Raphaëlle Marie Richieri' ${ }^{10}$, Philippe Domenech ${ }^{12}$, Corentin Rabu'12, Luc Mallet ${ }^{12}$, Liova Yon ${ }^{12}$, Laurent Schmitt ${ }^{1}$, Florian Stephan ${ }^{13}$, Guillaume Vaiva ${ }^{14}$, Michel Walter ${ }^{13}$, Pierre-Michel Llorca ${ }^{4}$, Philippe Courtet ${ }^{11}$, Marion Leboyer ${ }^{12}$, Wissam El-Hage ${ }^{7}$ and Bruno Aouizerate ${ }^{9}$

'Service de Psychiatrie et de Psychologie Médicale de l'adulte, Centre Expert Dépression Résistante FondaMental, CHRU de Toulouse, Hôpital Purpan, Toulouse, France, ${ }^{2}$ Service de Psychiatrie clinique, Centre Expert Dépression Résistante FondaMental, EA 481 Neurosciences, Université de Bourgogne Franche Comté, Besançon, France, ${ }^{3}$ Service de Psychiatrie clinique, Centre Expert Dépression Résistante FondaMental, Centre Investigation Clinique 1431-INSERM, EA 481 Neurosciences, Université de Bourgogne Franche Comté, Besançon, France, ${ }^{4}$ Service de Psychiatrie de l'adulte B, Centre Expert Dépression Résistante FondaMental, CHU de Clermont-Ferrand, Clermont-Ferrand, France, ${ }^{5}$ Service de Psychiatrie adulte, Centre Expert Dépression Résistante FondaMental, Hôpital Fernand-Widal, Paris, France, ${ }^{6}$ Service de Psychiatrie de l'adulte, CS 10217, Centre Expert Dépression Résistante FondaMental, CHU de Grenoble, Hôpital Nord, Grenoble, France, ${ }^{7}$ Clinique Psychiatrique Universitaire, Centre Expert Dépression Résistante FondaMental, Inserm U1253 imaging and Brain:iBrain, CHRU de Tours, Tours, France, ${ }^{8}$ Service Universitaire de Psychiatrie adulte, Centre Expert Dépression Résistante FondaMental, Centre Hospitalier Le Vinatier, Bron cedex, France, ${ }^{9}$ Pôle de Psychiatrie Générale et Universitaire, Centre Expert Dépression Résistante FondaMental, CH Charles Perrens, Bordeaux, France, ${ }^{10}$ Pôle Psychiatrie, Centre Expert Dépression Résistante FondaMental, CHU La Conception, Marseille, France, ${ }^{1}$ Département des Urgences et Post-Urgences Psychiatriques, Centre Expert Dépression Résistante FondaMental, CHRU Lapeyronie, Montpellier, France, ${ }^{12}$ Pôle de Psychiatrie des Hôpitaux Universitaires, Centre Expert Dépression Résistante FondaMental, Hôpital Henri Mondor, Créteil, France, ${ }^{13}$ Service de Psychiatrie de l'adulte, Centre Expert Dépression Résistante FondaMental, CHU de Brest, Hôpital de Bohars, Bohars, France, ${ }^{14}$ Service de Psychiatrie adulte, Centre Expert Dépression Résistante FondaMental, CHRU de Lille, Hôpital Fontan 1, Lille, France

Background: Major depression is characterized by (i) a high lifetime prevalence of $16-17 \%$ in the general population; (ii) a high frequency of treatment resistance in around 20-30\% of cases; (iii) a recurrent or chronic course; (iv) a negative impact on the general functioning and quality of life; and (v) a high level of comorbidity with various psychiatric and non-psychiatric disorders, high occurrence of completed suicide, significant burden along with the personal, societal, and economic costs. In this context, there is an important need for the development of a network of expert centers for treatment-resistant depression (TRD), as performed under the leadership of the Fondation FondaMental.

Methods: The principal mission of this national network is to establish a genuine prevention, screening, and diagnosis policy for TRD to offer a systematic, comprehensive, longitudinal, and multidimensional evaluation of cases. A shared electronic medical file is used referring to a common exhaustive and standardized set of assessment tools exploring psychiatric, non-psychiatric, metabolic, biological, and cognitive dimensions 
of TRD. This is paralleled by a medico-economic evaluation to examine the global economic burden of the disease and related health-care resource utilization. In addition, an integrated biobank has been built by the collection of serum and DNA samples for the measurement of several biomarkers that could further be associated with the treatment resistance in the recruited depressed patients. A French observational long-term follow-up cohort study is currently in progress enabling the extensive assessment of resistant depressed patients. In those unresponsive cases, each expert center proposes relevant therapeutic options that are classically aligned to the international guidelines referring to recognized scientific societies.

Discussion: This approach is expected to improve the overall clinical assessments and to provide evidence-based information to those clinicians most closely involved in the management of TRD thereby facilitating treatment decisions and choice in everyday clinical practice. This could contribute to significantly improve the poor prognosis, the relapsing course, daily functioning and heavy burden of TRD. Moreover, the newly created French network of expert centers for TRD will be particularly helpful for a better characterization of sociodemographic, clinical, neuropsychological, and biological markers of treatment resistance required for the further development of personalized therapeutic strategies in TRD.

Keywords: treatment-resistant depression, depressive disorder, assessment, network, innovative strategies

\section{INTRODUCTION}

Major depression is characterized by a high lifetime prevalence of $16-17 \%$ in the general population (1) with the possibility of evolution into a recurrent or chronic course (2) and a negative impact on the general functioning and quality of life (3). Major depression also has a high level of comorbidity with various psychiatric and non-psychiatric disorders $(1,4)$, with a high occurrence of completed suicide (4), and significant burden associated with the heavy personal, societal, and economic costs (4). Treatment-resistant depression (TRD) has been estimated to represent half of the overall treatment costs for major depression $(5,6)$. Although not clearly established in France, it can be assumed that approximately $20-30 \%$ of depressed patients experience TRD, as reported in Anglo-Saxon countries (7), and

\footnotetext{
Abbreviations: ATHF, Criteria for Rating Medication Trials for Antidepressant Failure; BAS, Brief Anxiety Scale; BFI, Big Five Inventory; CGI-S/I; Clinical Global Impression Severity/Improvement; CLVT, California Verbal Learning Test; C-SSRS, Columbia-SuicideSeverity Rating Scale; CSM, composite scale of morningness; CSRI, Client Service Receipt Inventory; CTQ, Child Trauma Questionnaire; EQ-5D-5L, EuroQol Five Dimension Five Level; FAST, Functional Analysis Screening Tool; GAF, Global Assessment of Functioning; ISF, Measure of Suicidal Ideation; IPAQ, International Physical Activity Questionnaire; LEAPS, Lam Employment Absence and Productivity Scale; MARS, Medication Adherence Rating Scale; MDQ, Mood Disorder Questionnaire; MINI, Mini International Neuropsychiatric Interview; PCL-S, Post Traumatic Stress Disorder Check List Scale; PRISE-M, Patient Rated Inventory of Side Effects; PSQI, The Pittsburgh Sleep Quality Index; QIDS-SR16, Quick Inventory of Depressive Symptomatology self report 16; SACHS, Bipolar Index; SHAPS, Snaith-Hamilton Pleasure Scale; SIS, Suicide Intent Scale; SPIN, Social Phobia Inventory; STAI-A, State-Trait Anxiety Inventory A; TMT A and B, Trail Making Test A and B; TRD, treatment-resistant depression; WAIS, Wechsler Adult Intelligence Scale; YMRS, Young Mania Rating Scale.
}

up to one half of patients responding only partially (8). TRD is currently defined by the failure of at least two attempts of antidepressant treatments administered sequentially at adequate dose and duration (8). Patients may be unresponsive to usual therapeutic strategies because of clinical features of the condition itself, factors interfering with the proper delivery of an optimal treatment such as under-dosing or poor adherence related to side effects, cognitions, comorbid disorders (psychiatric and nonpsychiatric), etc. (5, 6, 8-12). Although controversial (13), one of the major issue relies on the misdiagnosis of TRD instead of BP-II because hypomanic symptoms are difficult to detect, especially on a retrospective basis (14). Indeed, as reported by Judd et al. (15), patients with BP-II were symptomatic more than half of all follow-up weeks while depressive symptoms were largely more preponderant during the course as compared with hypomanic and cycling/mixed symptoms. Unrecognized bipolar spectrum illness increases substantially the risk for the inappropriate prescription of antidepressant treatment known to be associated with the occurrence of short-term resistance, poor tolerance, cycle acceleration, manic switch as well as late response loss after several months of recovery $(13,14,16,17)$. Thus, an inaccurate diagnosis almost always means a significant delay in appropriate and effective treatment based on mood stabilizers for bipolar patients. However, in this study, the adopted procedure tends to minimize hidden bipolar disorders behind TRD cases by using the structured Mini International Neuropsychiatric Interview (MINI) for the diagnostic evaluations coupled with the Mood Disorder Questionnaire (MDQ) useful for screening signs and symptoms of bipolar spectrum disorders.

Also, there is a heterogeneous etiology of TRD, including different environmental risk factors like childhood adversities 
coupled with multiple genetic determinants related to numerous genetic loci, and various epigenetic contributors involving a wide range of biological systems including the hypothalamic-pituitary-adrenal axis, immune function, monoamines, neurotrophic factors, etc. $(5,6,8,9,18)$. These factors can significantly modulate the therapeutic response while remission remains the aim of treatment for depression, given its implications for recovery of daily functioning and better long-term prognosis (7, 19-22). The absence of appropriate treatment increases the burden of depression and the resulting costs. This burden manifests itself in many ways including residual symptoms, cognitive impairment, relapse and recurrence, decreased quality of life, suicide, cardio- and cerebrovascular morbimortality, psychosocial alteration, work days lost, family impact, and economic costs $(4,23)$. Taken together, all these considerations underlie the particular relevance for the determination of contributing factors by a large and exhaustive assessment of patients suffering from TRD.

Many recommendations for clinical practice have been developed by various psychiatric societies around the world (24-28). These recommendations are primarily based on the analysis and classification of the scientific literature. They consider randomized, controlled and double-blind studies on large samples as offering the highest level of evidence. In spite of their rigor from a methodological and scientific point of view, the adaptability of these recommendations in everyday clinical practice can raise questions (29). High-level evidence studies, in fact, refer to selected samples of subjects, often free from comorbidities. They exclude characteristics such as advanced age, increased suicidal risk or high level of pharmacological resistance. These clinical situations are, however, frequently observed in daily clinical practice in the patient population suffering from TRD $(12,30)$.

In France, the need for improving the diagnosis, assessment, and management of psychiatric pathologies has led both the Ministry of Research and the Ministry of Health to support jointly the development of a national network of expert centers for Bipolar disorder (31), schizophrenia, TRD, and autism under the leadership of the foundation of scientific cooperation named "FondaMental" created in 2007. This article describes a new model of clinical collaboration between the expert centers and the regional community of clinicians, especially those general practitioners and psychiatrists who provide the first point of contact with health services for most TRD patients. Thus, within this network, we propose a systematic, comprehensive, longitudinal, and multidimensional assessment for patients who have failed to achieve remission after at least two adequate trials using different classes of antidepressants. The psychiatric, non-psychiatric, socioenvironmental, metabolic, biological, and cognitive dimensions of the current depressive episode are explored. A personalized evaluation and care program is delivered by a clinical expert highly specialized in the field of TRD. It also intends to narrow the gap between research knowledge and clinical practice. This represents an additional and locally accessible approach to the patients and their referent physician. The objective of this article is to disseminate information about this highly relevant project and to describe the standardized evaluation as proposed within the French network of centers specifically dedicated to TRD.

\section{METHODS}

\section{Mission of the National Expert Centers for TRD}

The principal mission of this national network is to establish a genuine prevention, screening, and diagnosis policy for TRD:

- Care: setting up a national and European network of expert centers-pluridisciplinary diagnosis and screening platforms-making it possible to follow patient cohorts with the contribution of an individual computerized medical file system common to all centers (e-Resistant Depression). This should allow access to personalized medicine primarily based on the elaboration of a strategy of care consistent with available data of the Evidence-Based Medicine and the monitoring of clinical outcomes via repeated assessments over time.

- Research: bringing together a national network of public and private researchers, linked to fundamental research platforms (mainly referring to biochemistry, molecular biology, genetic, and brain imaging), an approach that has already led to major discoveries. One of the aims is to improve staging and evaluation of innovative therapeutic options according to new scientific hypotheses, such as the inflammation theory of major depression and treatment failure (32).

- Training health-care professionals and raising awareness in the workplace: disseminating knowledge about the risk factors for mental illnesses and about novel treatment strategies.

- Communication: changing the way in which psychiatric diseases are generally perceived by the general population, and by opinion leaders, to substantially decrease stigmatization.

This operating care system offers a systematic, comprehensive, longitudinal, and multidimensional evaluation of cases of TRD by sharing a common set of assessment tools exploring separately psychiatric, non-psychiatric, metabolic, biological, genetic and cognitive dimensions of major depression. This is paralleled by a medico-economic evaluation for examining the global economic burden of the disease and related health-care resource utilization. For this purpose, the shared e-resistant depression medical file (e-Resistant Depression) and database (FACE-DR) were developed by the Fondation FondaMental to collect and store all these data. In addition, an integrated biobank intimately connected to FACE-DR is now being established with the primary goal of the collection of serum, plasma, DNA, RNA samples for the measurement of several biomarkers that could further be associated with treatment resistance in depressed patients (Figure 1).

\section{Network of Centers}

The French network of expert centers for resistant depression consists of 13 specialized care centers hosted within academic departments of Psychiatry widely distributed across France (Paris/Créteil, Paris Fernand-Widal, Besançon, Bordeaux, Brest, Clermont-Ferrand, Grenoble, Marseille, Montpellier, Lille, Lyon, Toulouse, and Tours). A multidisciplinary team of clinical representatives from FondaMental formed a working group to select the appropriate instruments for the clinical and 


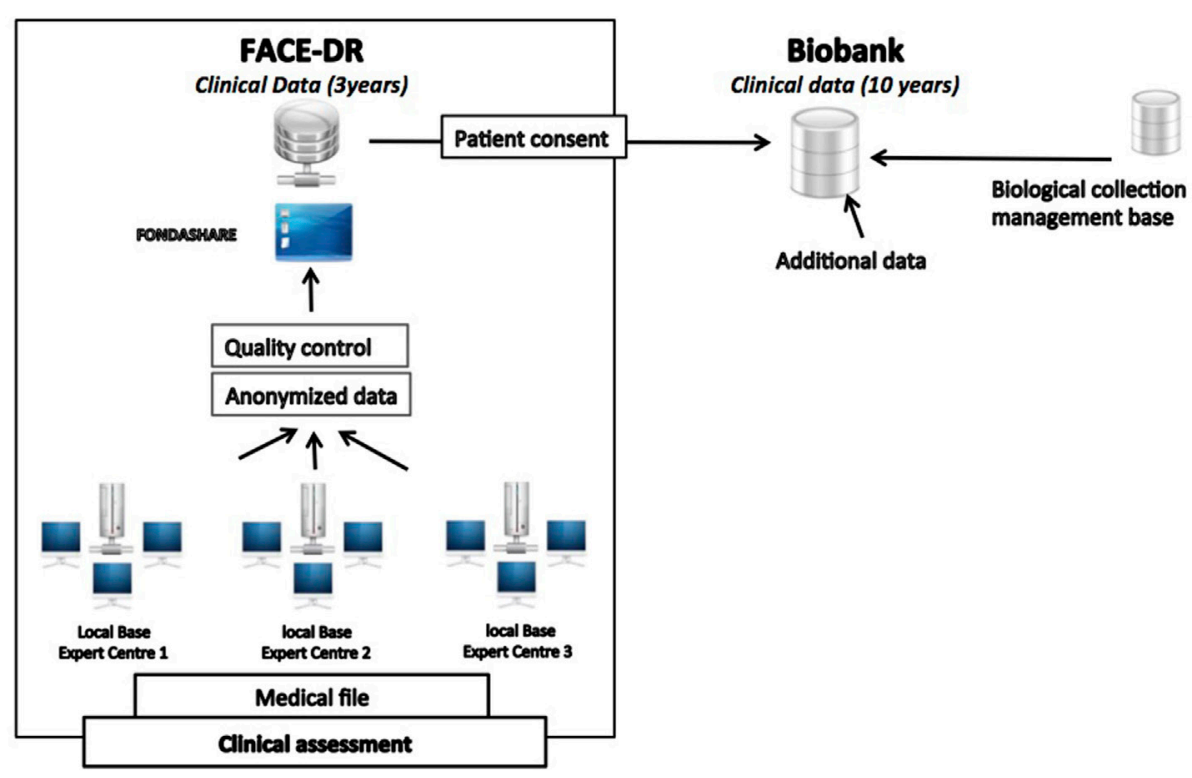

FIGURE 1 | Treatment-Resistant Depression Network organization throughout the French territory.

biological assessments. These teams are composed of, at least, a psychiatrist, a nurse, a neuropsychologist and a secretary within each center. Valid and reliable observer- and self-rating scales were prioritized, and all those involved in patient assessments received intensive training in the use of the measures they employ.

\section{Cohort of Patients}

A general practitioner or psychiatrist, who afterward will receive a detailed evaluation report along with some suggestions for clinical issues and therapeutic interventions, refers patients to be assessed in expert centers. Patients are clinically unresponsive to two successive and adequate sequences of antidepressants from two different pharmacological classes corresponding to at least stage II of the staging criteria proposed by Thase for defining TRD (33).

Before participating in the full assessment, patients are interviewed by a psychiatrist at the expert center to:

- Confirm the diagnosis of TRD according to the DSM-IV (34) criteria with moderate to severe symptoms (MADRS $\geq 20$ ), the level of resistance indicated by the classification of Thase and Rush (33) ( $\geq 2$ ), and assess the need to perform the full evaluation.

- Exclude bipolar disorders, psychotic disorders, OCD, eating disorders (with BMI < 15), somatoform disorders, and mood disorders related to substance abuse or misuse.

- Inform the patient about the formal assessment procedure and schedule the appointments with different health professionals within the expert centers comprising at least a psychiatrist, a nurse, and a neuropsychologist. Patients with TRD are then invited to participate and complete the assessment protocol over a period of two consecutive days.

\section{Data Collection}

An electronic health-care record system for a common national database was implemented through the development of a webbased application, e-resistant depression ( designed to collate all assessment data for clinical monitoring, research, and treatment purposes. Access to the system is carefully regulated and approval was obtained from the ethical committee and the committee in charge of the safety of computerized databases (French CNIL: DR-2015-673). To optimize data entry and retrieval, free text input has been minimized, and drops down lists and other approaches leading to standardized inputs chosen when possible. The XML format is used to transfer data from e-resistant-depression $(\subset)$ into an anonymous national database.

\section{Assessment Procedure}

Patients benefit at inclusion from an exhaustive clinical assessment (e-Resistant Depression) followed by systematic evaluations during four consecutive years, which are designed to identify: (i) clinical characteristics of resistance with psychological, non-psychiatric and metabolic data, (ii) socioenvironmental factors including daily routines, sport exercise, diet and stress-related factors such as early life traumatic experiences conferring high sensitivity to subsequent negative events over the lifespan which is expected to further influence the course of major depression and therapeutic response, and (iii) economic impact assessed by several indicators including number and duration of hospitalizations, number of visits to psychiatrists, general practitioners, pharmacological and nonpharmacological treatment consumption, work productivity, and health-related quality of life.

For this purpose, all centers have adopted the same package of evaluations and the different members of the center perform the full assessment. Table 1 provides a list of the self- and 
TABLE $1 \mid$ Instruments.

\begin{tabular}{|c|c|c|}
\hline Description & $\begin{array}{l}\text { Rater-administered } \\
\text { instruments }\end{array}$ & $\begin{array}{l}\text { Self-administered } \\
\text { instruments }\end{array}$ \\
\hline Depression severity & MADRS & QIDS-SR16 \\
\hline Self-esteem & & Rosenberg \\
\hline Manic severity & YMRS & \\
\hline Manic polarity & & MDQ, Altman \\
\hline Anxiety severity & BAS & STAI-A \\
\hline Emotional reactivity & & MATHYS \\
\hline Impulsivity & & Barratt \\
\hline Suicide & ISF, C-SSRS, SIS & \\
\hline Overall severity/improvement & CGI-S/I & \\
\hline General functioning & FAST/GAF & \\
\hline Personality traits & $\mathrm{BFI}$ & \\
\hline If comorbid social phobia & SPIN & \\
\hline Traumatic events & PCL-S & CTQ \\
\hline Stressful life events and impact & Paykel/Amiel-Lebigre & \\
\hline $\begin{array}{l}\text { Type/quantities care needs and } \\
\text { resources }\end{array}$ & CSRI & \\
\hline Side effects & & Prise M \\
\hline Therapeutic adherence & & MARS \\
\hline Work productivity and absence & LEAPS & \\
\hline Diet & & Diet questionnaire \\
\hline Physical activity & & $\begin{array}{l}\text { Physical activity } \\
\text { questionnaire }\end{array}$ \\
\hline Physical/mental health & & $E Q-5 D-5 L$ \\
\hline $\begin{array}{l}\text { Sleep quality, sleep/awake cycle, } \\
\text { drowsiness }\end{array}$ & & PSQI/CSM/Epworth \\
\hline
\end{tabular}

CSM, composite scale of morningness; EQ-5D-5L, EuroQol Five Dimension Five Level; FAST, Functional Analysis Screening Tool; GAF, Global Assessment of Functioning; MDQ, Mood Disorder Questionnaire; PSQI, The Pittsburgh Sleep Quality Index; QIDSSR16, Quick Inventory of Depressive Symptomatology self report; SIS, Suicide Intent Scale; SPIN, Social Phobia Inventory; STAI-A, State-Trait Anxiety Inventory A; YMRS, Young Mania Rating Scale; BFI, Big Five Inventory; PCL-S, Post Traumatic Stress Disorder Check List Scale; CGI-S/l; Clinical Global Impression Severity/Improvement; C-SSRS, Columbia-Suicide Severity Rating Scale; CSRI, Client Service Receipt Inventory; CTQ, Child Trauma Questionnaire; ISF, Measure of Suicidal Ideation; LEAPS, Lam Employment Absence and Productivity Scale; MARS, Medication Adherence Rating Scale.

observer-rated measures included at each visit performed over two consecutive days.

For each patient, the members of the center collect sociodemographic characteristics as well as clinical data related to the assessment of symptom severity, overall functional and quality-of-life impairment (MADRS, Young Mania Rating Scale, Functional Analysis Screening Tool, Global Assessment of Functioning, and EuroQol Five Dimension Five Level) (35-39), past and present history of major depression (MINI), psychiatric and somatic comorbidities, identification of previous and current pharmacological treatments (ATHF) (40) with adverse effects (Patient Rated Inventory of Side Effects) (41) and compliance (Medication Adherence Rating Scale) (42), determination of circadian typology (The Pittsburgh Sleep Quality Index, composite scale of morningness, and Epworth) (43-45), occurrence of suicidal events (ISF, Suicide Intent Scale, Columbia-Suicide Severity Rating Scale) (46-48), along with social, environmental and medico-economic data examining childhood trauma exposure (Child Trauma Questionnaire) (49) and stressful life events (Paykel) (50), physical exercise practice (International
Physical Activity Questionnaire) (51), dietary habits with the daily caloric intake, functioning at work (Lam Employment Absence and Productivity Scale) (52) and patient's use of medical health and social care services (Client Service Receipt Inventory) (53) (Table 1) (54-63). All these clinical evaluations are coupled with the examination of cognitive functions (attention, memory, psychomotor speed, flexibility, etc.), standard biological data (complete blood count, electrolytes, hepatic enzymes, creatinine clearance, etc.), metabolic tests (glycemia, cholesterolemia, etc.), morning cortisol, thyroid function, and vitamin status (D, B9, B12, etc.).

\section{Feedback to the Clinicians}

One of the major roles of the expert centers is to provide feedback to the clinicians regarding the proposals for care. These reports cover both diagnosis, clinical and treatment issues. As the evaluation is carried out by several different experts, the document sent to the clinicians is structured as the report of a multidisciplinary clinical meeting. In addition, the network intends to propose formalized recommendations on TRD for clinicians through joined sponsorship with the French Association of Biological Psychiatry and Neuropsychopharmacology.

\section{Biobanking}

A biobank was gradually developed and implemented within the network of the expert centers for resistant depression. After collecting signed written informed consent, each included patient is sampled at the beginning of the first visit within the Center of Clinical Investigation working locally in close collaboration with each of the expert centers. Samples are then transferred and stored at the Mondor CRB (Créteil) for further research projects developed within the network.

Building this biobank should enable the identification of new biomarkers and precise mechanisms of resistance with the identification of immunological, neuroendocrine, biochemical, genetic, epigenetic and cellular mechanisms regulating the signaling pathways that are supposed to be impaired in resistant depression. For this purpose, the biobank is composed of serum, plasma, DNA, RNA, etc. to be able to measure several biomarkers associated with the immune (pro-inflammatory cytokines and enzymatic pathways), neuroendocrine (pituitary-adrenal and thyroid axes), and monoaminergic systems (serotonin, norepinephrine, dopamine), or implicated in neurogenesis, neuroprotection (e.g., BDNF), and in genetic/epigenetic mechanisms.

\section{Longitudinal Follow-up}

Each patient enrolled into the cohort is evaluated every six months over the next 4 years (Figure 2). Table 2 summarizes the evaluation tools used at each visit. The objective of these followup visits is to evaluate the course of depressive symptoms and related clinical dimensions such as clinical remission, residual symptoms, relapses, recurrences, etc.

At the end of each visit, a report is sent to the doctor who referred the patient to the center. As described earlier, the results of the main evaluations are provided in these reports, and a clear diagnosis is given as well as a relevant proposal for therapeutic management. Therefore, from the overall clinical and paraclinical 


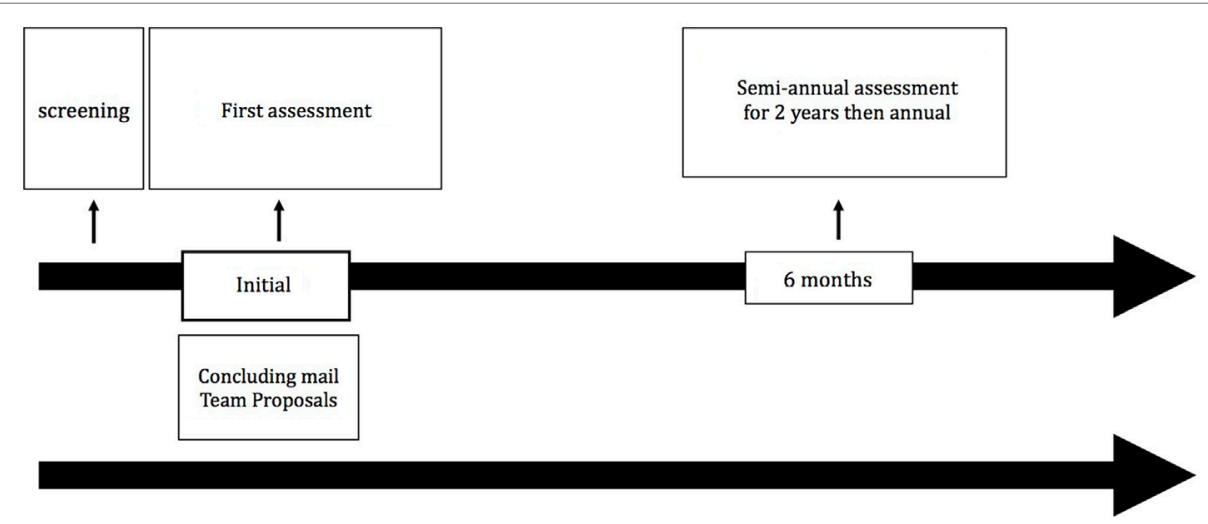

Follow-up within the usual framework

FIGURE 2 | Follow-up of an individual patient within the French Treatment-Resistant Depression Network.

assessments carried out and in relation to recommendations of good practice, individualized treatment interventions that may include innovative therapeutic strategies such as brain stimulation techniques are considered.

\section{Analysis Plan}

Data will be analyzed using SPSS version 22 (Armonk, NY, USA: IBM Corp.). As described elsewhere (7, 12, 64), means and SDs will be presented for continuous variables, and counts and percentages for discrete variables. Parametric analysis-ofvariance methods will be used for the repeated comparisons of the overall symptom severity (i.e., MADRS, QIDS-SR-16 scores) over the 4-year follow-up period. Post hoc tests will be conducted to make pairwise comparisons. Chi-square tests will be applied for the comparisons of sociodemographic characteristics, and percentages of depressed patients showing satisfactory response (i.e., $\geq 50 \%$ decrease in MADRS or QIDS-SR-16 score from baseline), achieving remission (i.e., MADRS score $\leq 10$ or QIDS-SR-16 score $\leq 5$ ) or experiencing relapse (i.e., MADRS score $\geq 15$ or QIDS-SR-16 score $\geq 11$ ) across experimental visits. For the calculation of sample size, we formulate the hypothesis that the depressed patients in our sample will be considered as remitters in at least $35 \%$ of cases at mid-term after the proposed treatment strategies referring to standard international guidelines, thereby enabling to obtain the remission rate observed following a first-line antidepressant therapy in the earlier collaborative study $\operatorname{STAR}^{\star} \mathrm{D}(7)$. This therefore contrasts with the remission rate of less than $15 \%$ which was reported after failure of more than two previous antidepressant treatments in this pivotal STAR ${ }^{\star} \mathrm{D}$ trial (7). On this basis, the required number of subjects is calculated for a two-sided test with a risk $\alpha$ of $5 \%$ and a power $1-\beta$ of $95 \%$ leading to the inclusion of a total of 130 resistant depressed subjects in our cohort to allow the demonstration of a difference at least equal to $20 \%$ in the remission rate as compared with that found in the STAR* study. We will recruit 130 additional subjects in our cohort to take into account and cover any protocol deviations, dropouts, or missing data, etc.

\section{Dissemination Plan}

The significant findings will be disseminated through following three distinct and complementary strategies: (1) publications in international scientific journals, (2) communications in congress, and (3) symposia and conference for health care providers under supervision of the principle investigators within each university hospital affiliated to our national network. Other specific actions will be developed enabling the targeted diffusion of the most relevant results and including multidisciplinary brainstorming sessions in the setting of a regional coordination of care for difficult-to-treat depressed patients, teaching activity for medical students and residents in psychiatry, continuing medical education for mental health professionals (general practitioners, psychiatrists, psychologists, nurses, etc.), and educational training during summer schools for master and Ph.D. students, postdoctoral fellows, especially. Finally, more general informative meetings will be regularly conducted by the expert centers, designed for the affected patients with their caregivers and commonly focused on the presentation of major clinical, therapeutic, and functional issues related to resistant depression.

\section{DISCUSSION}

By offering a systematic, complete, longitudinal, and multidimensional evaluation of each TRD case, using shared medical records containing common assessment tools exploring separately the psychiatric, non-psychiatric dimensions, metabolic functions, biological, and cognitive impairments, we aim at making accessible to all patients with a diagnosis of TRD, the most personalized and adapted treatment strategies possible. Indeed, it seems important to be able to apply the therapeutic guidelines to improve the prognosis of TRD. Guo et al. (65) showed an improvement in the management using measurement-based care for outpatients with moderate to severe major depression. Indeed, the responses as well as remission rates are higher, and adjustment of therapeutic doses of antidepressant is more straightforward in the measurement-based care group. 
TABLE 2 | Standardized scales of assessment.

\begin{tabular}{|c|c|c|c|c|c|c|}
\hline Assessment & Scale & Pre-screening & First assessment & $\begin{array}{c}\text { Months } 6 \\
\text { and } 18\end{array}$ & $\begin{array}{c}\text { Months } 12 \\
\text { and } 36\end{array}$ & $\begin{array}{c}\text { Months } 24 \\
\text { and } 48\end{array}$ \\
\hline \multirow[t]{3}{*}{ Current mood states and residual symptoms } & $-\mathrm{MINI}$ & $x$ & & & & \\
\hline & - QIDS-SR16 & $x$ & $x$ & $x$ & $x$ & $x$ \\
\hline & - MADRS & $x$ & $x$ & $x$ & $x$ & $x$ \\
\hline \multirow[t]{2}{*}{ Suicidal behavior } & - ISF, SIS & & $x$ & & & $x$ \\
\hline & - C-SSRS & & $x$ & $x$ & $x$ & $x$ \\
\hline \multirow[t]{2}{*}{ Sleep } & $\begin{array}{l}\text { - CSM } \\
\text { - Epworth }\end{array}$ & & $x$ & & $x$ & $x$ \\
\hline & - PSQI & & $x$ & $x$ & $x$ & $x$ \\
\hline \multirow[t]{2}{*}{ Functioning and severity of disorder } & - FAST & & $x$ & & & $x$ \\
\hline & $\begin{array}{l}\text { - CGI-S } \\
\text { - EGF } \\
\text { - ED-5Q-5L }\end{array}$ & & $x$ & $x$ & $x$ & $x$ \\
\hline Care course & - CSRI & & $x$ & & $x$ & $x$ \\
\hline $\begin{array}{l}\text { Treatment: } \\
\text { - Psychotropic } \\
\text { - Psychotherapy } \\
\text { - Brain stimulation }\end{array}$ & $\begin{array}{l}\text { - MARS } \\
\text { - PRISE-M } \\
\text { - ATHF } \\
\text { - PTHF } \\
\text { - e-Resistant Depression }\end{array}$ & & $x$ & $x$ & $x$ & $x$ \\
\hline Cognitive functioning & $\begin{array}{l}\text { - CLVT } \\
\text { - WAIS } \\
\text { - TMT A } \\
\text { - TMT B } \\
\text { - Stroop test } \\
\text { - verbal Fluency }\end{array}$ & & $x$ & & $x$ & $x$ \\
\hline
\end{tabular}

BAS, Brief Anxiety Scale; CLVT, California Verbal Learning Test; CSM, composite scale of morningness; FAST, Functional Analysis Screening Tool; MDQ, Mood Disorder Questionnaire; PSQI, The Pittsburgh Sleep Quality Index; QIDS-SR16, Quick Inventory of Depressive Symptomatology self report; SHAPS, Snaith-Hamilton Pleasure Scale; SIS, Suicide Intent Scale; SPIN, Social Phobia Inventory; TMT A and B, Trail Making Test A and B; WAIS, Wechsler Adult Intelligence Scale; YMRS, Young Mania Rating Scale; MINI, Mini International Neuropsychiatric Interview; PCL-S. Post Traumatic Stress Disorder Check List Scale; PRISE-M, Patient Rated Inventory of Side Effects; SACHS, Bipolar Index; ATHF, Criteria for Rating Medication Trials for Antidepressant Failure; C-SSRS, Columbia-Suicide Severity Rating Scale; CSRI, Client Service Receipt Inventory; CTQ, Child Trauma Questionnaire; ISF, Measure of Suicidal Ideation; LEAPS, Lam Employment Absence and Productivity Scale; MARS, Medication Adherence Rating Scale.

As proposed in the expert centers, the administration of a wide range of clinical instruments and neuropsychological tests for the comprehensive assessment of depressed patients could be perceived negatively, especially with regard to the long time, attentional demand and sustained effort required for completion. However, clear information about the study design is delivered before final acceptance of participation. All these assessments are scheduled over three half-days on two consecutive days but 
interleaved systematically with frequent rest periods to prevent sufficiently a gradual decline in concentration and excessive fatigability. Phone reminders are even scheduled at least one week before each visit to limit dropouts. As supported in the study by Rush (66), measurement-based care also offers the advantage of better preparing and engaging the patients in shared decision making and adherence to long-term care needs, thereby familiarizing themselves with relevant tools currently used for monitoring their clinical symptoms and side effects caused by standard treatments.

Moreover, diagnostic and clinical heterogeneity appears to be a major obstacle for an exact understanding of the pathophysiology of mental illnesses and, in particular, major depression. Although there is a widely demonstrated hereditary component (67) the identification of genetic risk factors has proven difficult even in meta-analyses of genome-wide association studies (68).

Similarly, efforts to develop new treatments have stagnated, partly due to a lack of new biological targets and the choice of the people most likely to benefit from them (69). All these challenges have been attributed in part to the fact that our diagnostic system assigns a unique label to a syndrome that is not unitary but could be caused by distinct pathological processes, which would require different treatments. Indeed, major depression is a widespread disease presumably represented by a large number of patient subgroups that must be identified precisely to propose adapted therapeutic strategies.

Our national network must be part of the existing regional health care system. Although adherence to treatment guidelines has been shown to improve clinical outcomes (65), there are barriers to their application, including the fact that guidelines are often viewed as "top-down" measures. One aim of the network is to make available the standard recommendations derived from the currently used guidelines for each patient. It should bridge the gap between evidence-based medicine and routine practice.

In addition, clinical research is an important issue within the network. The electronic health-care record system for each expert center is connected to a national database and data on this large clinically representative cohort of TRD cases will allow prospective follow-up and comparative-effectiveness studies. Combination of clinical, biological, genetic, and epigenetic data could contribute to a more precise definition of separate clusters of major depression for a more specific and tailored management of this pathology. To refine the diagnostic and therapeutic approach, by focusing on more precise clusters, the main lines of future research are focused on: (i) the role of comorbidities, beyond what are now defined as risk factors for resistance [cardiovascular, neurological, metabolic pathologies, etc. (70-72)]; (ii) the role and impact of traumatic factors; (iii) the presence of suicidal ideation or behaviors; (iv) the functional repercussions; (v) resistance to treatments; (vi) neurocognitive profiles; (vii) genetic, epigenetic, immuno-inflammatory, neuroendocrine, and neurochemical markers, etc. In this context, patients benefiting from the evaluation within the expert centers, are asked to participate in various national and European research studies implemented in partnership with the "Fondation FondaMental" addressing jointly clinical, pathophysiological, and therapeutic issues (73).

\section{CONCLUSION}

The adopted integrative approach shared within the network of expert centers for resistant depression is a compelling model for the precise characterization of sociodemographic, clinical, neuropsychological, biological, and metabolic factors of treatment resistance and to further develop innovative and personalized strategies through the multi-faceted questions of assessment, management, and treatment of major depression. This is one of the best options for changing the poor prognosis of TRD, reducing the deleterious impact on daily functioning and quality of life and thereby lowering the serious societal and economic burden related to high direct and indirect costs of TRD.

\section{ETHICS STATEMENT}

Ethics approval and consent to participate: the database (clinical data and biobanking) was validated by an ethics committee: CNIL (French CNIL: DR-2015-673). Consent for publication: all patients in the expert centers receive oral and written information on the possible use of their data for research purposes. Availability of data and material: all the material used for the assessment is validated in French.

\section{AUTHOR CONTRIBUTIONS}

$\mathrm{AY}, \mathrm{DB}, \mathrm{EH}, \mathrm{WE}-\mathrm{H}$, and $\mathrm{BA}$ realized the initial frame of the manuscript. The authors have made corrections after proofreading. All the authors participated in the recruitment of patients.

\section{ACKNOWLEDGMENTS}

The authors would like to thank Fondation FondaMental.

\section{FUNDING}

FondaMental Network is supported by AstraZeneca, Janssen, Lilly, Lundbeck, Otsuka, Sanofi, Servier, and Takeda. Through a scientific partnership, Fondation FondaMental and AstraZeneca join forces to fill the gap in clinical data on resistant depressive disorders Jansenn has been supporting the social missions of the "Fondation FondaMental" since 2008. Lilly France supports young researchers. Lundbeck is committed to supporting the "Fondation FondaMental" in disseminating knowledge through the support of the annual conference cycle. Otsuka Pharmaceutical France supports the Fondation FondaMental Foundation's knowledge dissemination mission. Servier has been providing institutional support since 2008 to the "Fondation FondaMental's" actions. Takeda supports the research mission of "Fondation FondaMental." 


\section{REFERENCES}

1. Kessler RC, Berglund P, Demler O, Jin R, Merikangas KR, Walters EE. Lifetime prevalence and age-of-onset distributions of DSM-IV disorders in the National Comorbidity Survey Replication. Arch Gen Psychiatry (2005) 62:593-602. doi:10.1001/archpsyc.62.6.593

2. Eaton WW, Shao H, Nestadt G, Lee HB, Lee BH, Bienvenu OJ, et al. Populationbased study of first onset and chronicity in major depressive disorder. Arch Gen Psychiatry (2008) 65:513-20. doi:10.1001/archpsyc.65.5.513

3. IsHak WW, Mirocha J, James D, Tobia G, Vilhauer J, Fakhry H, et al. Quality of life in major depressive disorder before/after multiple steps of treatment and oneyear follow-up. Acta Psychiatr Scand (2015) 131:51-60. doi:10.1111/acps.12301

4. Lépine J-P, Briley M. The increasing burden of depression. Neuropsychiatr Dis Treat (2011) 7:3-7. doi:10.2147/NDT.S19617

5. Greden JF. The burden of disease for treatment-resistant depression. J Clin Psychiatry (2001) 62(Suppl 16):26-31.

6. Olsen LR, Mortensen EL, Bech P. Prevalence of major depression and stress indicators in the Danish general population. Acta Psychiatr Scand (2004) 109:96-103. doi:10.1046/j.0001-690X.2003.00231.x

7. Rush AJ, Trivedi MH, Wisniewski SR, Nierenberg AA, Stewart JW, Warden D, et al. Acute and longer-term outcomes in depressed outpatients requiring one or several treatment steps: a STAR ${ }^{\star} \mathrm{D}$ report. Am J Psychiatry (2006) 163:1905-17. doi:10.1176/ajp.2006.163.11.1905

8. Fava M, Davidson KG. Definition and epidemiology of treatment-resistant depression. Psychiatr Clin North Am (1996) 19:179-200. doi:10.1016/ S0193-953X(05)70283-5

9. Malhi GS, Parker GB, Crawford J, Wilhelm K, Mitchell PB. Treatment-resistant depression: resistant to definition? Acta Psychiatr Scand (2005) 112:302-9. doi:10.1111/j.1600-0447.2005.00602.x

10. Bennabi D, Aouizerate B, El-Hage W, Doumy O, Moliere F, Courtet P, et al. Risk factors for treatment resistance in unipolar depression: a systematic review. J Affect Disord (2015) 171:137-41. doi:10.1016/j.jad.2014.09.020

11. Souery D, Oswald P, Massat I, Bailer U, Bollen J, Demyttenaere K, et al. Clinical factors associated with treatment resistance in major depressive disorder: results from a European multicenter study. J Clin Psychiatry (2007) 68:1062-70. doi:10.4088/JCP.v68n0713

12. Balestri M, Calati R, Souery D, Kautzky A, Kasper S, Montgomery S, et al. Socio-demographic and clinical predictors of treatment resistant depression: a prospective European multicenter study. J Affect Disord (2016) 189:224-32. doi:10.1016/j.jad.2015.09.033

13. Correa R, Akiskal H, Gilmer W, Nierenberg AA, Trivedi M, Zisook S. Is unrecognized bipolar disorder a frequent contributor to apparent treatment resistant depression? J Affect Disord (2010) 127:10-8. doi:10.1016/j.jad.2010.06.036

14. Berk M, Dodd S. Bipolar II disorder: a review. Bipolar Disord (2005) 7:11-21. doi:10.1111/j.1399-5618.2004.00152.x

15. Judd LL, Akiskal HS, Schettler PJ, Coryell W, Endicott J, Maser JD, et al. A prospective investigation of the natural history of the long-term weekly symptomatic status of bipolar II disorder. Arch Gen Psychiatry (2003) 60:261-9. doi:10.1001/archpsyc.60.3.261

16. Ghaemi SN, Rosenquist KJ, Ko JY, Baldassano CF, Kontos NJ, Baldessarini RJ. Antidepressant treatment in bipolar versus unipolar depression. Am J Psychiatry (2004) 161:163-5. doi:10.1176/appi.ajp.161.1.163

17. Perlis RH, Uher R, Ostacher M, Goldberg JF, Trivedi MH, Rush AJ, et al. Association between bipolar spectrum features and treatment outcomes in outpatients with major depressive disorder. Arch Gen Psychiatry (2011) 68:351-60. doi:10.1001/archgenpsychiatry.2010.179

18. El-Hage W, Leman S, Camus V, Belzung C. Mechanisms of antidepressant resistance. Front Pharmacol (2013) 4:146. doi:10.3389/fphar.2013.00146

19. Rush AJ, Kraemer HC, Sackeim HA, Fava M, Trivedi MH, Frank E, et al. Report by the ACNP Task Force on response and remission in major depressive disorder. Neuropsychopharmacology (2006) 31:1841-53. doi:10.1038/ sj.npp.1301131

20. Paykel ES, Ramana R, Cooper Z, Hayhurst H, Kerr J, Barocka A. Residual symptoms after partial remission: an important outcome in depression. Psychol Med (1995) 25:1171-80. doi:10.1017/S0033291700033146

21. Miller IW, Keitner GI, Schatzberg AF, Klein DN, Thase ME, Rush AJ, et al. The treatment of chronic depression, part 3: psychosocial functioning before and after treatment with sertraline or imipramine. J Clin Psychiatry (1998) 59:608-19. doi:10.4088/JCP.v59n1108
22. Van Londen L, Molenaar RP, Goekoop JG, Zwinderman AH, Rooijmans HG Three- to 5-year prospective follow-up of outcome in major depression. Psychol Med (1998) 28:731-5. doi:10.1017/S0033291797006466

23. Thomas CM, Morris S. Cost of depression among adults in England in 2000. Br J Psychiatry (2003) 183:514-9. doi:10.1192/bjp.183.6.514

24. American Psychiatric Association. Practice guideline for the treatment of patients with major depressive disorder (revision). Am J Psychiatry (2000) 157:1-45.

25. Lam RW, McIntosh D, Wang J, Enns MW, Kolivakis T, Michalak EE, et al. Canadian network for mood and anxiety treatments (CANMAT) 2016 clinical guidelines for the management of adults with major depressive disorder: section 1. Disease burden and principles of care. Can J Psychiatry (2016) 61:510-23. doi:10.1177/0706743716659416

26. Anderson IM, Ferrier IN, Baldwin RC, Cowen PJ, Howard L, Lewis G, et al. Evidence-based guidelines for treating depressive disorders with antidepressants: a revision of the 2000 British Association for Psychopharmacology guidelines. J Psychopharmacol (2008) 22:343-96. doi:10.1177/0269881107088441

27. Goldberg D. The "NICE Guideline" on the treatment of depression. Epidemiol Psichiatr Soc (2006) 15:11-5.

28. Bauer M, Pfennig A, Severus E, Whybrow PC, Angst J, Möller H-J, et al. Task Force on Unipolar Depressive Disorders. World Federation of Societies of Biological Psychiatry (WFSBP) guidelines for biological treatment of unipolar depressive disorders, part 1: update 2013 on the acute and continuation treatment of unipolar depressive disorders. World J Biol Psychiatry (2013) 14:334-85. doi:10.3109/15622975.2013.804195

29. Samalin L, Guillaume S, Courtet P, Abbar M, Lancrenon S, Llorca P-M. Methodological differences between pharmacological treatment guidelines for bipolar disorder: what to do for the clinicians? Compr Psychiatry (2013) 54:309-20. doi:10.1016/j.comppsych.2012.10.001

30. De Carlo V, Calati R, Serretti A. Socio-demographic and clinical predictors of non-response/non-remission in treatment resistant depressed patients: a systematic review. Psychiatry Res (2016) 240:421-30. doi:10.1016/j.psychres. 2016.04.034

31. Henry C, Etain B, Mathieu F, Raust A, Vibert J-F, Scott J, et al. A French network of bipolar expert centres: a model to close the gap between evidence-based medicine and routine practice. J Affect Disord (2011) 131: 358-63. doi:10.1016/j.jad.2010.11.013

32. Miller AH, Raison CL. The role of inflammation in depression: from evolutionary imperative to modern treatment target. Nat Rev Immunol (2016) 16:22-34. doi:10.1038/nri.2015.5

33. Thase ME, Rush AJ. When at first you don't succeed: sequential strategies for antidepressant nonresponders. J Clin Psychiatry (1997) 58(Suppl 13):23-9.

34. Frances A, Pincus HA, First MB. American Psychiatric Association DSM$I V$-TR. 4ème édition texte révisé ed. Washington, DC (2000). Available from: http://dsm.psychiatryonline.org/

35. Montgomery SA, Asberg M. A new depression scale designed to be sensitive to change. Br J Psychiatry (1979) 134:382-9. doi:10.1192/bjp.134.4.382

36. Young RC, Biggs JT, Ziegler VE, Meyer DA. A rating scale for mania: reliability, validity and sensitivity. Br J Psychiatry (1978) 133:429-35. doi:10.1192/ bjp.133.5.429

37. Janssen MF, Pickard AS, Golicki D, Gudex C, Niewada M, Scalone L, et al. Measurement properties of the EQ-5D-5L compared to the EQ-5D-3L across eight patient groups: a multi-country study. Qual Life Res (2013) 22:1717-27. doi:10.1007/s11136-012-0322-4

38. Rosa AR, Sánchez-Moreno J, Martínez-Aran A, Salamero M, Torrent C, Reinares $\mathrm{M}$, et al. Validity and reliability of the Functioning Assessment Short Test (FAST) in bipolar disorder. Clin Pract Epidemiol (2007) 3:5. doi:10.1186/1745-0179-3-5

39. Dufton BD, Siddique CM. Measures in the day hospital. I. The global assessment of functioning scale. Int J Partial Hosp (1992) 8:41-9.

40. Oquendo MA, Baca-Garcia E, Kartachov A, Khait V, Campbell CE, Richards $\mathrm{M}$, et al. A computer algorithm for calculating the adequacy of antidepressant treatment in unipolar and bipolar depression. J Clin Psychiatry (2003) 64:825-33. doi:10.4088/JCP.v64n0714

41. Rush AJ, Fava M, Wisniewski SR, Lavori PW, Trivedi MH, Sackeim HA, et al. Sequenced treatment alternatives to relieve depression $\left(\mathrm{STAR}^{\star} \mathrm{D}\right)$ : rationale and design. Control Clin Trials (2004) 25:119-42. doi:10.1016/ S0197-2456(03)00112-0

42. Misdrahi D, Verdoux H, Llorca P-M, Baylé F-J. [Therapeutic adherence and schizophrenia: the interest of the validation of the French 
translation of Medication Adherence Rating Scale (MARS)]. L'Encephale (2004) 30:409-10.

43. Buysse DJ, Reynolds CF, Monk TH, Berman SR, Kupfer DJ. The Pittsburgh Sleep Quality Index: a new instrument for psychiatric practice and research. Psychiatry Res (1989) 28:193-213. doi:10.1016/0165-1781(89)90047-4

44. Johns MW. A new method for measuring daytime sleepiness: the Epworth sleepiness scale. Sleep (1991) 14:540-5. doi:10.1093/sleep/14.6.540

45. Smith PA, Brown DF, Di Milia L, Wragg C. The use of the Circadian Type Inventory as a measure of the circadian constructs of vigour and rigidity. Ergonomics (1993) 36:169-75. doi:10.1080/00140139308967869

46. Beck RW, Morris JB, Beck AT. Cross-validation of the Suicidal Intent Scale. Psychol Rep (1974) 34:445-6. doi:10.2466/pr0.1974.34.2.445

47. Paykel ES, Myers JK, Lindenthal JJ, Tanner J. Suicidal feelings in the general population: a prevalence study. Br J Psychiatry (1974) 124:460-9. doi:10.1192/bjp.124.5.460

48. Posner K, Brown GK, Stanley B, Brent DA, Yershova KV, Oquendo MA, et al. The Columbia-Suicide Severity Rating Scale: initial validity and internal consistency findings from three multisite studies with adolescents and adults. Am J Psychiatry (2011) 168:1266-77. doi:10.1176/appi.ajp.2011.10111704

49. Bernstein DP, Fink L, Handelsman L, Foote J, Lovejoy M, Wenzel K, et al. Initial reliability and validity of a new retrospective measure of child abuse and neglect. Am J Psychiatry (1994) 151:1132-6. doi:10.1176/ajp.151.8.1132

50. Paykel ES. Contribution of life events to causation of psychiatric illness. Psychol Med (1978) 8:245-53. doi:10.1017/S003329170001429X

51. Craig CL, Marshall AL, Sjöström M, Bauman AE, Booth ML, Ainsworth BE, et al. International physical activity questionnaire: 12-country reliability and validity. Med Sci Sports Exerc (2003) 35:1381-95. doi:10.1249/01.MSS. 0000078924.61453.FB

52. Lam RW, Michalak EE, Yatham LN. A new clinical rating scale for work absence and productivity: validation in patients with major depressive disorder. BMC Psychiatry (2009) 9:78. doi:10.1186/1471-244X-9-78

53. Beecham J, Knapp M. Costing psychiatric interventions. In: Thornicroft G, Brewin C, Wing JK, editors. Measuring Mental Health Needs. 2nd ed. London: Gaskell/Royal College of Psychiatrists (1999).

54. Altman EG, Hedeker D, Peterson JL, Davis JM. The Altman Self-Rating Mania Scale. Biol Psychiatry (1997) 42:948-55. doi:10.1016/S0006-3223(96)00548-3

55. Hirschfeld RM, Williams JB, Spitzer RL, Calabrese JR, Flynn L, Keck PE, et al. Development and validation of a screening instrument for bipolar spectrum disorder: the Mood Disorder Questionnaire. Am J Psychiatry (2000) 157:1873-5. doi:10.1176/appi.ajp.157.11.1873

56. Henry C, M'Bailara K, Mathieu F, Poinsot R, Falissard B. Construction and validation of a dimensional scale exploring mood disorders: MAThyS (multidimensional assessment of thymic states). BMC Psychiatry (2008) 8:82. doi:10.1186/1471-244X-8-82

57. Tyrer P, Owen RT, Cicchetti DV. The brief scale for anxiety: a subdivision of the comprehensive psychopathological rating scale. J Neurol Neurosurg Psychiatry (1984) 47:970-5. doi:10.1136/jnnp.47.9.970

58. Lesur A, Bonnet D, Vicaut E, Lempérière T. [Tyrer's Brief Scale for anxiety used with outpatients. First validation in the French language]. L'Encephale (1989) 15:535-42.

59. Goldberg LR. An alternative "description of personality": the big-five factor structure. J Pers Soc Psychol (1990) 59:1216-29. doi:10.1037/0022-3514.59. 6.1216

60. Blanchard EB, Jones-Alexander J, Buckley TC, Forneris CA. Psychometric properties of the PTSD Checklist (PCL). Behav Res Ther (1996) 34:669-73. doi:10.1016/0005-7967(96)00033-2

61. Patton JH, Stanford MS, Barratt ES. Factor structure of the Barratt impulsiveness scale. JClin Psychol (1995) 51:768-74. doi:10.1002/10974679(199511)51:6<768::AID-JCLP2270510607>3.0.CO;2-1

62. Wongpakaran T, Tinakon W, Wongpakaran N, Nahathai W. A comparison of reliability and construct validity between the original and revised versions of the Rosenberg Self-Esteem Scale. Psychiatry Investig (2012) 9:54-8. doi:10.4306/pi.2012.9.1.54

63. Connor KM, Davidson JR, Churchill LE, Sherwood A, Foa E, Weisler RH. Psychometric properties of the Social Phobia Inventory (SPIN). New selfrating scale. Br J Psychiatry (2000) 176:379-86. doi:10.1192/bjp.176.4.379

64. Nierenberg AA, Fava M, Trivedi MH, Wisniewski SR, Thase ME, McGrath PJ, et al. A comparison of lithium and T(3) augmentation following two failed medication treatments for depression: a STAR ${ }^{\star} \mathrm{D}$ report. Am J Psychiatry (2006) 163:1519-30; quiz 1665. doi:10.1176/ajp.2006.163.9.1519

65. Guo T, Xiang Y-T, Xiao L, Hu C-Q, Chiu HFK, Ungvari GS, et al. Measurementbased care versus standard care for major depression: a randomized controlled trial with blind raters. Am J Psychiatry (2015) 172:1004-13. doi:10.1176/ appi.ajp.2015.14050652

66. Rush AJ. Isn't it about time to employ measurement-based care in practice? Am J Psychiatry (2015) 172:934-6. doi:10.1176/appi.ajp.2015.15070928

67. Sullivan PF, Neale MC, Kendler KS. Genetic epidemiology of major depression: review and meta-analysis. Am J Psychiatry (2000) 157:1552-62. doi:10.1176/ appi.ajp.157.10.1552

68. Major Depressive Disorder Working Group of the Psychiatric GWAS Consortium, Ripke S, Wray NR, Lewis CM, Hamilton SP, Weissman MM, et al. A mega-analysis of genome-wide association studies for major depressive disorder. Mol Psychiatry (2013) 18:497-511. doi:10.1038/mp.2012.21

69. Pankevich DE, Altevogt BM, Dunlop J, Gage FH, Hyman SE. Improving and accelerating drug development for nervous system disorders. Neuron (2014) 84:546-53. doi:10.1016/j.neuron.2014.10.007

70. Gili M, Garcia-Toro M, Vives M, Armengol S, Garcia-Campayo J, Soriano JB, et al. Medical comorbidity in recurrent versus first-episode depressive patients. Acta Psychiatr Scand (2011) 123:220-7. doi:10.1111/j.16000447.2010.01646.x

71. Gili M, Comas A, García-García M, Monzón S, Antoni S-B, Roca M. Comorbidity between common mental disorders and chronic somatic diseases in primary care patients. Gen Hosp Psychiatry (2010) 32:240-5. doi:10.1016/j. genhosppsych.2010.01.013

72. Roca M, Gili M, Garcia-Garcia M, Salva J, Vives M, Garcia Campayo J, et al. Prevalence and comorbidity of common mental disorders in primary care. J Affect Disord (2009) 119:52-8. doi:10.1016/j.jad.2009.03.014

73. Kleiboer A, Smit J, Bosmans J, Ruwaard J, Andersson G, Topooco N, et al. European COMPARative Effectiveness research on blended Depression treatment versus treatment-as-usual (E-COMPARED): study protocol for a randomized controlled, non-inferiority trial in eight European countries. Trials (2016) 17:387. doi:10.1186/s13063-016-1511-1

Conflict of Interest Statement: AY: I acted in advisory capacities, carried out clinical studies in relation to the development of a medicine (Janssen), received travel allowance, gave presentations at meetings, and received remuneration for my input from the following pharmaceutical organizations: AstraZeneca, Janssen, Lundbeck, Otsuka, and Servier. DB has received honoraria from Lundbeck. EH: I acted in advisory capacities, carried out clinical studies in relation to the development of a medicine, received personal researches, studies or travel allowance, gave presentations at meetings, and received remuneration for my input from the following pharmaceutical organizations: AstraZeneca, BMS, Cellgene, Euthérapie-Servier, Janssen, Elli Lilly, Lundbeck, Otsuka, Pfizer, and Sanofi. And, I held a managerial position in Fondation FondaMental, Créteil, and the French Association of Biological Psychiatry. MG has received honoraria from Janssen-Cilag and Lundbeck. TD, PD, LM, and LS: no competing interest. OD has received honoraria from Lilly, AstraZeneca, Jansen, Servier, and Lundbeck. FH has received honoraria from AstraZeneca, a grant from Institut Servier and is currently supported by Fonds de recherche du Québec-Nature et technologies (grant number \#200123.). FS has received honoraria from Otsuka. GV has received speaker honoraria from Otsuka/Lundbeck (annual intervention at the reception day for new professors of psychiatry). WE-H has received speaker honoraria from Janssen, Lundbeck, Otsuka, and UCB. BA: as received speaker honoraria from Lundbeck, Janssen, and Eli Lilly. All other authors declare that the research was conducted in the absence of any commercial or financial relationships that could be construed as a potential conflict of interest.

Copyright $\odot 2017$ Yrondi, Bennabi, Haffen, Garnier, Bellivier, Bourgerol, Camus, D’Amato, Doumy, Haesebaert, Holtzmann, Lançon, Vignaud, Moliere, Nieto, Richieri, Domenech, Rabu, Mallet, Yon, Schmitt, Stephan, Vaiva, Walter, Llorca, Courtet, Leboyer, El-Hage and Aouizerate. This is an open-access article distributed under the terms of the Creative Commons Attribution License (CC BY). The use, distribution or reproduction in other forums is permitted, provided the original author(s) or licensor are credited and that the original publication in this journal is cited, in accordance with accepted academic practice. No use, distribution or reproduction is permitted which does not comply with these terms. 